\title{
Comparison of Mechanical, Assisted and Manual Harvest of Origanum vulgare L.
}

\author{
Antonio Comparetti $^{1}(\mathbb{D})$, Carlo Greco ${ }^{2, *(\mathbb{D}}$, Santo Orlando ${ }^{1, *(\mathbb{D})}$, Salvatore Ciulla ${ }^{3}$ \\ and Michele Massimo Mammano ${ }^{2}$
}

Citation: Comparetti, A.; Greco, C.; Orlando, S.; Ciulla, S.; Mammano, M.M. Comparison of Mechanical, Assisted and Manual Harvest of Origanum vulgare L. Sustainability 2022, 14, 2562. https://doi.org/ $10.3390 /$ su14052562

Academic Editors: Sabina Iole Giuseppina Failla, Elio Romano, Simone Bergonzoli,

Giampaolo Schillaci and

Hossein Azadi

Received: 30 November 2021

Accepted: 22 February 2022

Published: 23 February 2022

Publisher's Note: MDPI stays neutral with regard to jurisdictional claims in published maps and institutional affiliations.

Copyright: (C) 2022 by the authors. Licensee MDPI, Basel, Switzerland. This article is an open access article distributed under the terms and conditions of the Creative Commons Attribution (CC BY) license (https:// creativecommons.org/licenses/by/ $4.0 /)$.
1 Department of Agricultural, Food and Forest Sciences, University of Palermo, Viale delle Scienze, Building 4, 90128 Palermo, Italy; antonio.comparetti@unipa.it

2 Council for Agricultural Research and Economics (CREA), Research Centre Protection and Certification, 90011 Bagheria, Italy; massimo.mammano@crea.gov.it

3 Association of Producers SiciliaBio, Via Vittorio Emanuele, 100, 92026 Favara, Italy; salvatoreciulla@libero.it

* Correspondence: carlo.greco@crea.gov.it (C.G.); santo.orlando@unipa.it (S.O.)

\begin{abstract}
In Italy, the production of Origanum vulgare L. is lower than the national market demand, so there is an increasing interest in this crop, even if the manual harvest and bunch binding represent ca. $60 \%$ of the production cost. The aim of this work is to evaluate the harvest efficiency, as well as the working capacity, productivity and quality of mechanical harvesting by means of a reaperbinder designed for cereal and forage crops and assisted harvesting by means of a long-reach edge trimmer. In fact, the final aim is to suggest a machine and a method for oregano harvesting that could significantly reduce the time and, therefore, the cost of this crop operation, while achieving a product quality similar to that obtained by manual harvesting. Tests of mechanical and assisted harvesting were carried out using a reaper-binder after modifying it (i.e., reducing its forward speed, cutting height and bunch size to improve its working capacity, productivity and quality) and an edge trimmer, respectively. The tests of mechanical and assisted harvesting were compared with manual harvesting. In the testing field, with an irregular shape and an area of one hectare, nine rows were selected and divided into three replications, each comprising three tests, i.e., mechanical, assisted and manual harvesting. The modified reaper-binder allowed us to achieve working capacity and productivity rates much higher than those obtained with manual harvesting. Moreover, its harvest quality, in terms of bunch weight and binding height, favourably compares with that manually obtained. Furthermore, the edge trimmer allowed us to achieve working capacity and productivity rates lower than those obtained by means of the reaper-binder but much higher than in manual harvesting. Thus, the reaper-binder can minimise the harvest time and, therefore, cost while harvesting bunches slightly bigger than those manually harvested, even if it requires a high initial investment cost. Instead, the edge trimmer can be a cheap solution for reducing the harvest time and cost. Therefore, mechanical and assisted harvesting could spread oregano production in areas of inland Sicily and other Mediterranean regions that are often cultivated with low-profit herbaceous plant species or lie fallow. Thus, it would be possible to increase farmers' incomes and job opportunities, as well as preventing or minimising the hydrogeological instability in these areas.
\end{abstract}

Keywords: oregano; reaper-binder; edge trimmer; working capacity; working productivity; working quality

\section{Introduction}

Aromatic and medicinal plants have become very popular in European and global markets during the last decade. Among these plants, Origanum species, belonging to the Lamiaceae family, have been known as culinary and medicinal plants since ancient times. Some species, including Origanum vulgare L., are rich in essential oils and are commonly known as oregano [1]. Origanum vulgare L. is an aromatic and perennial sub-shrub that is widely spread all over Europe, Asia and North Africa [2]. In Italy, the production of 
Origanum vulgare $\mathrm{L}$. is lower than the national market demand, so there is an increasing interest in this crop.

This species is considered extremely variable, both in its morphological features and chemical composition. For its specific biological character and significant economic importance, Origanum vulgare has been placed in the List of Priority Species in Europe [3]. Even if six subspecies of Origanum vulgare have been recognised [2,4], many varieties, landraces, forms, ecotypes and cultivars are nowadays available for stakeholders. The interest in Origanum vulgare $\mathrm{L}$. is increasing because of its antioxidant, antimicrobial, aromatic, aperitif, digestive, antiseptic and expectorant properties [5]. The economic value of officinal plant derivates is also increasing because of the demand from the pharmaceutical industry. In fact, products imported from other countries have the disadvantages of customs delays, product deterioration and pollution during transportation and storage, as well as missing information about product origin and health, harvest time and harvest method. The need for cheap raw materials and high-quality products suggests the development of growing methods aimed at decreasing production costs without reducing the product quality.

Origanum vulgare can also be cultivated in the "marginal" hilly and mountainous areas of southern Italy that are not suitable for other crops. The creation of quality marks (e.g., DOC and DOP) and a closer connection between farmers and processing industries could build up an "integrated" rural development and contribute to solving one of the main agricultural problems, i.e., the need for cultivating alternative crops that could increase job possibilities and profit.

The production of Origanum vulgare L. in Sicily is characterised by high quantity and quality. It is believed that the cultivation of oregano can provide Sicilian farmers with high added value also on degraded sloping lands in the semi-arid areas of the island.

In Sicily, oregano can be considered a convenient alternative to traditional crops, as it allows a diversification of agricultural production, as well as new jobs and profit integration. Even if this species is mostly used for food seasoning, its major appeal comes from the possibility of using it as a raw material for producing, inside small and local agro-food industries, food flavourings or additives with a higher price than fresh herbs [6].

The harvest time is determined based on the yield quality, e.g., the essential oil content immediately after flowering, which usually happens from mid-June to late August.

The plants are cut $5-8 \mathrm{~cm}$ above the ground. If the crop is irrigated immediately after the first harvest, a second harvest may be possible.

The harvest time of oregano depends on the commercial use of the product:

- beginning of flowering, for herb production;

- full blooming, when the oil content is at its maximum, for essential oil production;

- at maximum blooming (higher than $50 \%$ ) and plant coverage (leaves and flowers), for food use $[7,8]$.

The crop yield and the oil content are quite constant during the flowering period, while the oil content of the leaves is very low during the autumn (October) harvest.

Dry oregano yield may reach $1.5-3.0 \mathrm{t} \mathrm{ha}^{-1}$, whereas the total duration of its cultivation may exceed 10-11 years. A rough estimate of an average crop yield indicates a value of $20 \mathrm{t} \mathrm{ha}^{-1}$ in a 4-year crop. Full crop performance can be achieved after the first year of transplanting. The harvest index (ratio flowers weight/total weight) is ca. $50-55 \%$ in the first harvest, due to the high incidence of stems, and ca. 60-70\% in the second mowing, which is usually carried out in October [9].

Even if the harvest is generally manual in Italy, it can be mechanically carried out by means of reaper-binders designed for cereal and forage crops but modified in order to cut the stems at $5-10 \mathrm{~cm}$ above the ground.

In order to manually harvest one hectare, having an average yield of 5-6 tha ${ }^{-1}$ of fresh product, 27 working hours are needed, while the same quantity can be harvested in $6-8 \mathrm{~h}$ by means of a reaper-binder.

In some foreign countries, the harvest is totally mechanical. For oregano intended for food use or essential oil extraction, mowing is carried out by leaving the product in 
windrows until the cut plants have lost ca. $60 \%$ of their water content. Then, for oregano intended for food use, threshing is carried out and the obtained product is stored inside bags. Instead, for oregano intended for essential oil extraction, it is possible to press bales of $25-35 \mathrm{~kg}$, which are transported to industry. The obtained oregano has a lower quality, as it becomes dark under the sun and loses many aromatic characteristics. Currently, mower-loaders that cut, load and immediately transport the product to the farm centre are mainly used so that the drying follows there [8].

In Italy, until now, there has been low interest in this crop, above all because manual harvesting and bunch binding represent ca. $60 \%$ of the production cost [10].

The first tests carried out using the reaper-binder before modifications [11,12] allowed us to obtain bunches of a large size and density, as well as a high binding point, located in their most tender parts. Therefore, it was possible to observe fungi diseases and/or fermentation, which caused a loss of a part of the product. During the above tests, stems piled up in the conveyor and binding unit of the machine because of its too high forward speed, so both time and product losses were recorded.

Thus, the aim of this work is to evaluate the harvest efficiency, as well as the working capacity, productivity and quality, of mechanical harvesting, by means of a reaper-binder designed for cereal and forage crops, and assisted harvesting, by means of a long-reach edge trimmer. In fact, the final aim is to suggest a machine and a method for oregano harvesting in order to significantly reduce the time and, therefore, the cost of this crop operation, while achieving a product quality similar to that obtained by manual harvesting.

\section{Materials and Methods}

Growing tests were carried out in a testing field of the Association of Producers SiciliaBio, located in the territory of Sant' Angelo Muxaro (Agrigento, Italy), Lon $13^{\circ} 38^{\prime} 18^{\prime \prime} \mathrm{E}$, Lat $37^{\circ} 27^{\prime} 50^{\prime \prime} \mathrm{N}$, in July 2020.

In the testing field, with an irregular shape and an area of $1 \mathrm{ha}$, nine rows $90 \mathrm{~m}$ long were selected. The above nine rows were divided into three replications, each constituted by three tests:

(1) mechanical harvesting;

(2) assisted harvesting;

(3) manual harvesting.

In this testing field, oregano was cultivated according to the crop management methods traditionally applied to this species in Sicily. The rootings used for the propagation were obtained from a local wild genotype previously classified as Origanum vulgare, subsp. viridulum (Martrin-Donos Nyman) or O. heracleoticum L. Previously prepared rootings were transplanted in the field in winter 2010, with plant distances of $1.0 \times 0.5 \mathrm{~m}$, thereby achieving a plant density of 20,000 plants ha ${ }^{-1}$. The field was managed according to organic agriculture principles: organic fertilisation was carried out before transplanting by applying $2 \mathrm{t} \mathrm{ha}^{-1}$ of cattle manure, which was buried using a plough at a depth of ca. $40 \mathrm{~cm}$. The field weeds were removed through two shallow soil tillage operations using a rotary tiller and a tine harrow, respectively, at a depth of ca. $5 \mathrm{~cm}$ during the early spring of each year.

During each replication of each test, the times of the various harvest operations were measured in order to compute the working capacity and productivity, as well as the harvest efficiency (ratio between the weight of the harvested crop and that of the total crop, \%).

During the mechanical harvesting test, the following times were measured: cutting and binding; turning on headlands; machine setting up.

During the assisted harvesting test, the following times were measured: cutting; collection from the ground and binding; machine setting up.

For both the mechanical and assisted harvesting tests, the machine working quality, i.e., the average weight and binding height of the bunch, was also determined. 
The results of both the mechanical and assisted harvesting tests were compared with those of the manual harvesting, carried out by an operator using a sickle. During the test of manual harvesting, the cutting and binding time was measured.

Moreover, for each test, the bunches were collected along three rows, in order to measure their height and weight.

A one-way ANOVA with a significance level of 0.05 was applied to the collected data in order to discover if the differences among the three harvesting tests were significant or not for each considered response (i.e., parameter) [13].

Then, the Tukey method with a 95\% confidence level was applied to the collected data in order to take into account the influence of the three harvesting tests on the nine considered responses.

\subsection{Mechanical Harvesting Test}

For the mechanical harvesting test, the crop was harvested by means of a BCS 622 reaper-binder with $10 \mathrm{~kW}$ engine power and three forward speeds (Figure 1).

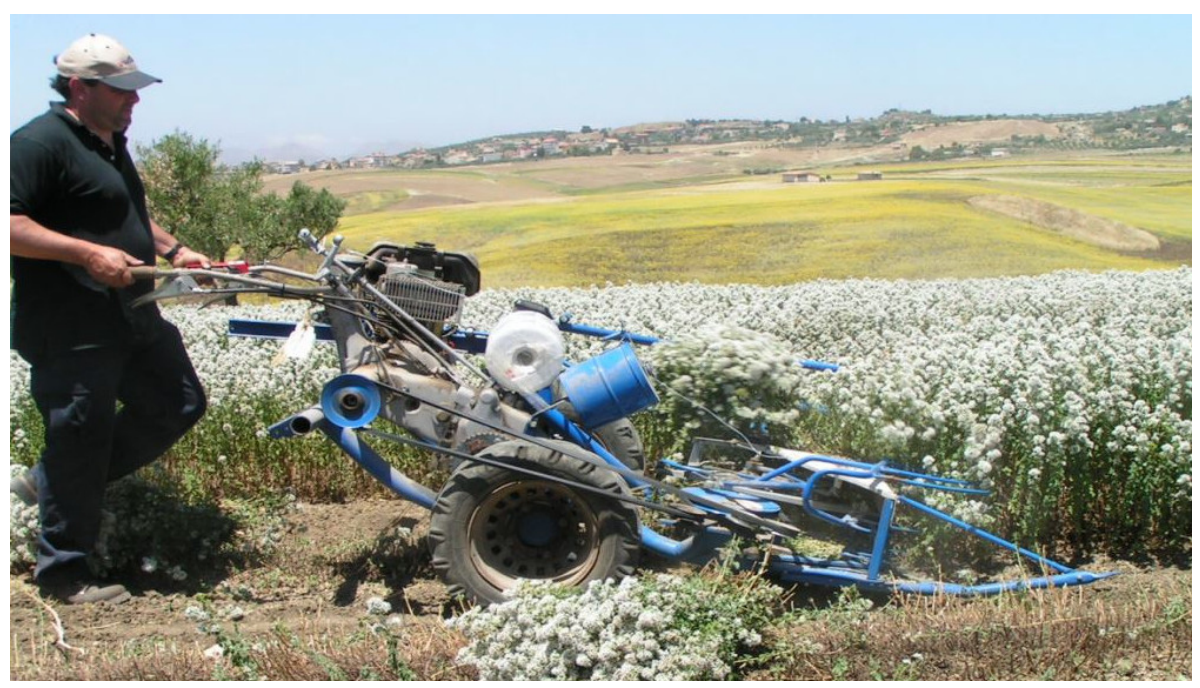

Figure 1. Modified BCS 622 reaper-binder used during the mechanical harvesting test.

The machine has two driving wheels equipped with tyres. It is driven by a walking operator holding two handlebars, equipped with the main driving controls (i.e., accelerator, clutch and brakes). In one pass, the machine cuts and collects the stems and binds them in bunches, leaving them on the ground. The reaper-binder is equipped with a $1.20 \mathrm{~m}$-wide cutting bar with one blade that reciprocates with respect to a ledger plate with standard single fingers. The machine is equipped with a conveyor, constituted by two reciprocating forks, that insert the stems in an accumulation area. Here, the bunch, after reaching the desired size, is bound. The movement of the forks and the cutting bar is independent of the machine forward speed. The machine is equipped with a binding unit (Appleby), constituted by a needle and pliers, which knots the twine around the bunch.

It is possible to adjust the stem cutting height by varying (from 0.15 to $0.25 \mathrm{~m}$ ) the height above the ground of a support slide fixed under the cutting bar.

The mechanical harvesting test was carried out using a machine that was further modified [11,12] to reduce:

- $\quad$ its maximum forward speed, i.e., with different gears from 1.5 to $1.1 \mathrm{~m} \mathrm{~s}^{-1}$ (I), from 2.1 to $1.5 \mathrm{~m} \mathrm{~s}^{-1}$ (II), from 2.8 to $2.0 \mathrm{~m} \mathrm{~s}^{-1}$ (III), from 3.9 to $2.8 \mathrm{~m} \mathrm{~s}^{-1}$ (IV), from 1.7 to $1.2 \mathrm{~m} \mathrm{~s}^{-1}(\mathrm{R})$, by replacing its wheels (4.50-19) with a rolling circumference of $2234 \mathrm{~mm}$ with two others (5.00-15) with a lower rolling circumference of $1985 \mathrm{~mm}$ and mounting a final drive (chain reducer), constituted by two toothed wheels with a different number of teeth-Z1 with 32 and Z2 with 40, respectively (Figure 2); 
- $\quad$ its minimum cutting height (by $0.05 \mathrm{~m}$, by modifying the shape of the support slide of the cutting bar;

- the bunch size by also lowering its binding height;

- the bunch binding height by lifting the base of the conveyor and binding unit [12].

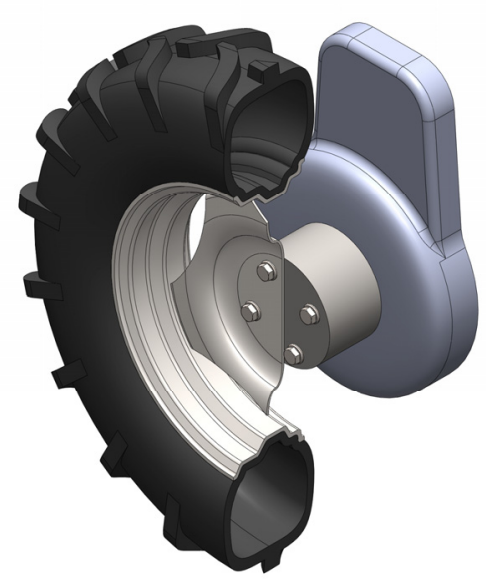

(a)

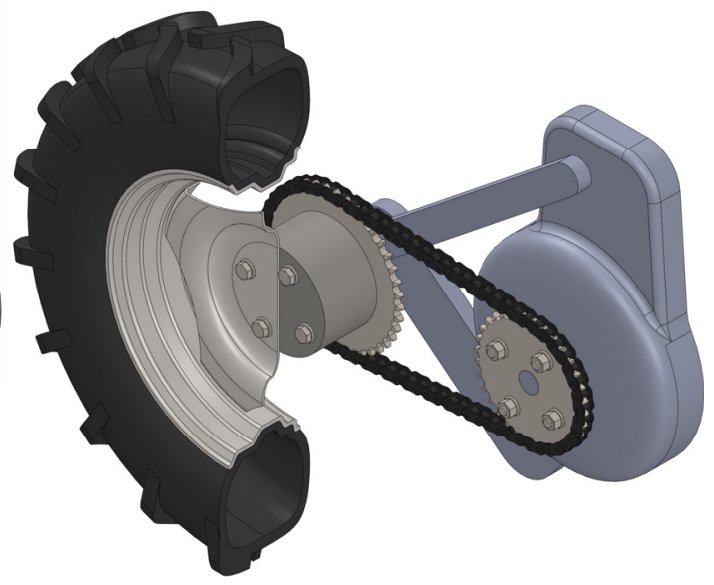

(b)

Figure 2. Detail of the modified BCS 622 reaper-binder where the added final drive (chain reducer), constituted by two toothed wheels, is shown: (a) original version; (b) modified version.

The mechanical harvesting test was carried out by two operators, of which one was the driver and the other collected the bunches left on the ground and loaded them inside boxes, on a trailer connected to a tractor, for storage in the shade.

By modifying the binding unit, the bunch size was reduced to a thickness similar to that of manual binding, while the working capacity, productivity and quality of the machine were improved with respect to manual harvesting, and the product losses on the field were also minimised.

\subsection{Assisted Harvesting Test}

The assisted harvesting test was carried out using a long-reach edge trimmer, McCulloch B33 PS, equipped with a $33 \mathrm{~cm}^{3}$ two-stroke petrol engine with a power output of $0.9 \mathrm{~kW}$, as well as an adjustable shaft and a pivoting cutting bar (Figure 3).

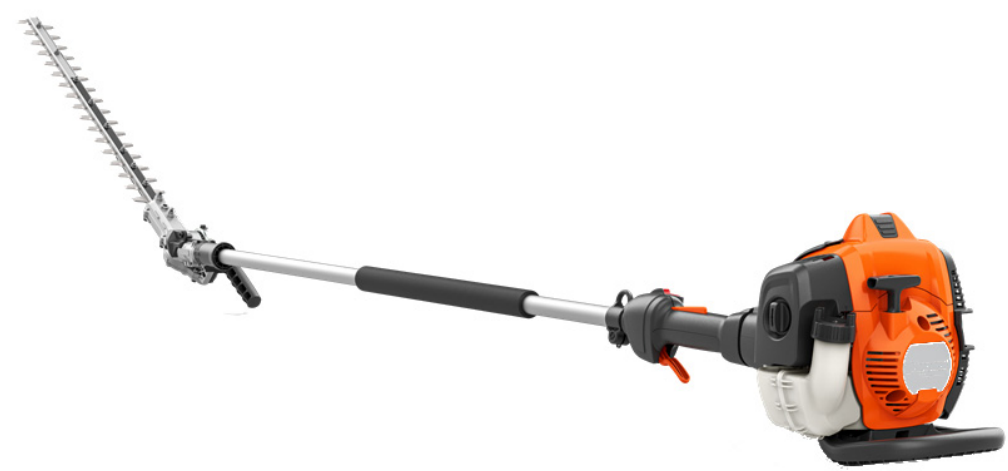

Figure 3. Long-reach edge trimmer, McCulloch B33 PS, used during the assisted harvesting test.

The assisted harvesting test was also carried out by two operators, of which one used the edge trimmer and the other collected the stems left on the ground and bound them in bunches. Every ca. $30 \mathrm{~min}$, both the operators collected the bunches left on the ground and loaded them on the above trailer. 


\section{Results and Discussion}

The average times of the various operations, carried out during the three harvest tests with reference to an area of 1 ha, are shown in Figure 4.

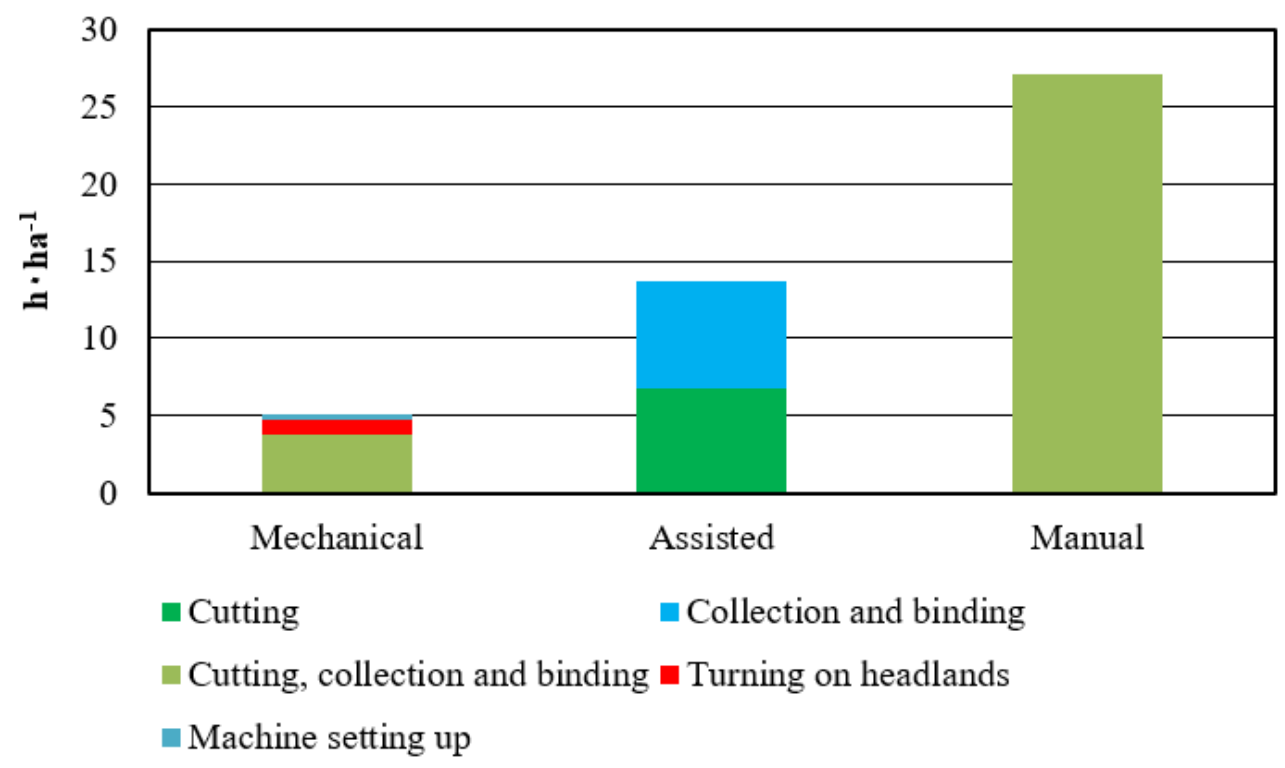

Figure 4. Average times of the various operations carried out during the three harvest tests with reference to an area of 1 ha (average data).

From Figure 4, it is possible to deduce that if a mechanical harvest is performed instead of a manual one, the total average time decreases by ca. $81 \%$. In contrast, if assisted harvesting is performed instead of a manual one, the total average time decreases by ca. $50 \%$.

The total average time of mechanical harvesting is constituted by cutting and binding time for ca. $74 \%$, turning (on headlands) time for ca. $20 \%$ and machine setting up for ca. $6 \%$.

The time for turning on headlands, as a percentage of the total time, depends on the row length: an increase in the row length should determine a decreased turning time as a percentage of the total time.

The average forward speed of the modified reaper-binder resulted was $0.98 \mathrm{~m} \mathrm{~s}^{-1}$, while that of the edge trimmer was $0.41 \mathrm{~m} \mathrm{~s}^{-1}$.

Therefore, the reaper-binder allowed average working capacity and productivity rates much higher than those obtained with manual harvesting.

Moreover, the edge trimmer allowed average working capacity and productivity rates lower than the reaper-binder but much higher than in the manual harvesting operation.

The average harvest efficiency of the mechanical harvesting test was $92 \%$, i.e., $4 \%$ lower than the $96 \%$ obtained in the assisted harvesting test. However, the average harvest efficiency of both the mechanical and assisted tests was lower than that $(98.5 \%)$ of the manual harvesting test. Yet, the edge trimmer produced low average product losses on the field, so the resulting average harvest efficiency was slightly lower than that of manual harvesting.

During the mechanical harvesting test, using the modified reaper-binder, the average bunch weight $(1.52 \mathrm{~kg})$ was higher than that required by the market $(0.25 \mathrm{~kg})$, while the average bunch binding height $(0.19 \mathrm{~m})$ was slightly higher than that obtained with manual harvest $(0.15 \mathrm{~m})$. Therefore, the harvest quality of the modified machine, in terms of bunch weight and binding height, favourably compares with that manually obtained.

According to the results of the one-way ANOVA with a significance level of 0.05, applied to the collected data shown in Table 1, it was possible to discover: 
- $\quad$ significant differences among the three harvesting tests for six out of nine considered responses, i.e., working capacity ( $p$-value $=0.000)$, working productivity $(p$-value $=0.000)$, working efficiency $(p$-value $=0.023)$, product losses on the field $(p$-value $=0.011)$, bunches per ha $(p$-value $=0.000)$ and bunch average weight $(p$-value $=0.000)$;

- no significant differences among the three harvest tests only for three out of nine considered responses, i.e., product not harvested $(p$-value $=0.070)$, cutting height $(p$-value $=0.559)$ and bunch binding height $(p$-value $=0.406)$.

Table 1. Working parameters of mechanical, assisted and manual harvesting tests (collected data).

\begin{tabular}{|c|c|c|c|c|c|c|c|c|c|}
\hline \multirow{2}{*}{$\begin{array}{c}\text { Harvest } \\
\text { Test }\end{array}$} & \multicolumn{3}{|c|}{ Mechanical ${ }^{1}$} & \multicolumn{3}{|c|}{ Assisted 1,2 } & \multicolumn{3}{|c|}{ Manual } \\
\hline & 1 & 2 & 3 & 1 & 2 & 3 & 1 & 2 & 3 \\
\hline Working capacity $\left(\mathrm{ha}^{-1}\right)$ & 0.198 & 0.21 & 0.187 & 0.149 & 0.146 & 0.145 & 0.037 & 0.04 & 0.035 \\
\hline $\begin{array}{l}\text { Working productivity (ha } \mathrm{h}^{-1} \\
\text { operator }^{-1} \text { ) }\end{array}$ & 0.099 & 0.107 & 0.091 & 0.07 & 0.076 & 0.074 & 0.037 & 0.04 & 0.035 \\
\hline Harvest efficiency (\%) & 87 & 94 & 90 & 93 & 98 & 97 & 98.5 & 98 & 98 \\
\hline Product losses on the field (\%) & 2.5 & 3.5 & 2.5 & 2 & 1 & 1.5 & 1 & 1 & 1.5 \\
\hline Product not harvested $(\%)$ & 10.5 & 2.5 & 7.5 & 5 & 1 & 1.5 & 0.5 & 1 & 0.5 \\
\hline Cutting height $(\mathrm{m})$ & 0.1 & 0.14 & 0.12 & 0.14 & 0.06 & 0.1 & 0.08 & 0.1 & 0.11 \\
\hline Bunches per ha (n) & 5130 & 5206 & 5198 & 32,084 & 31,930 & 31,865 & 31,365 & 31,492 & 31,463 \\
\hline Bunch average weight $(\mathrm{kg})$ & 1.4 & 1.6 & 1.53 & 0.23 & 0.28 & 0.24 & 0.24 & 0.27 & 0.27 \\
\hline Bunch binding height (m) & 0.22 & 0.17 & 0.18 & 0.13 & 0.16 & 0.19 & 0.15 & 0.17 & 0.19 \\
\hline
\end{tabular}

${ }^{1}$ Mechanical harvesting is performed by means of the reaper-binder, while assisted one is carried out by using the edge trimmer. ${ }^{2}$ Steam collection and bunch binding are manually performed.

Confidence intervals (95\% confidence level) on the means, calculated by using the Tukey method, allowed us to see the influence of the three harvest tests on the nine responses. This is illustrated in Figures 5-13.

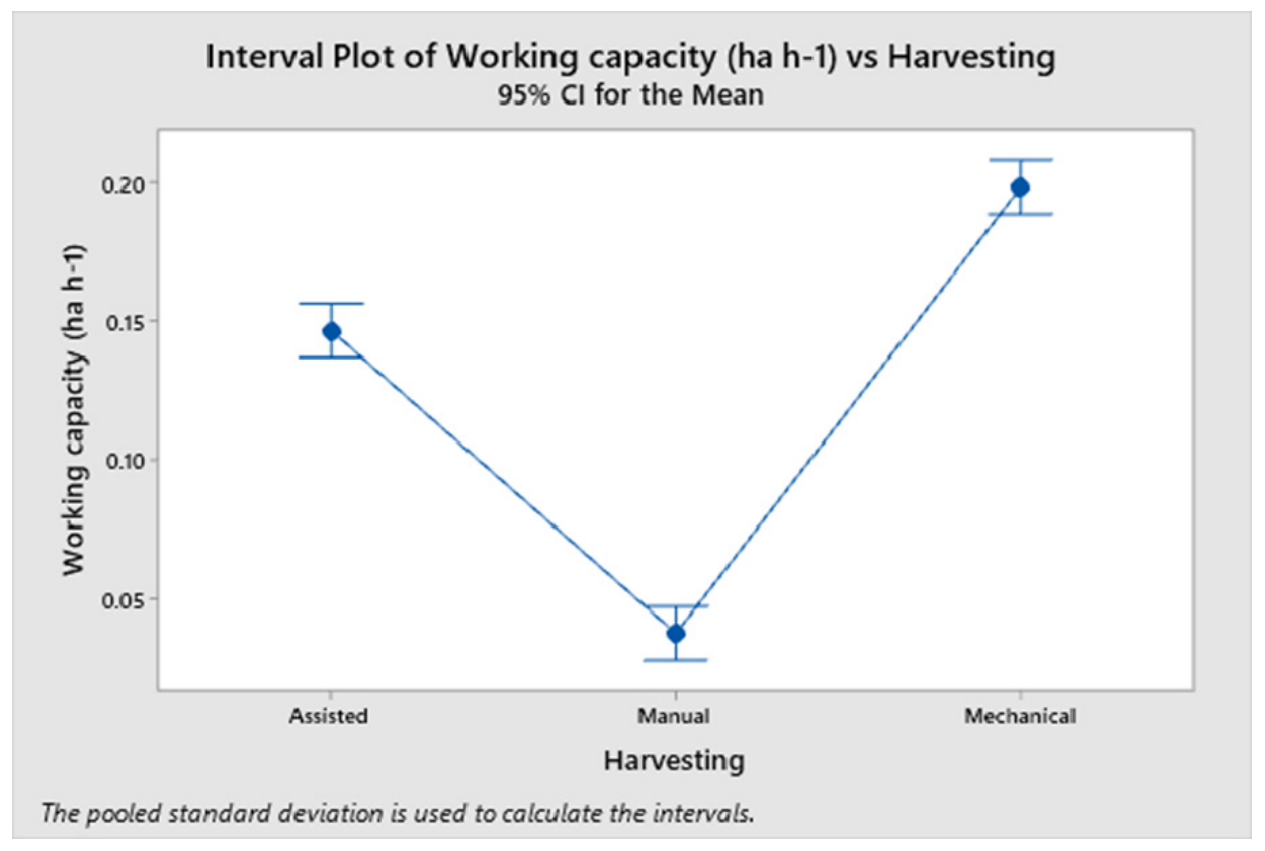

Figure 5. Results of Tukey method with a CI (Confidence Interval) of 95\%, applied to the raw data of working capacity for the three harvest tests $(p$-value $=0.000)$. 


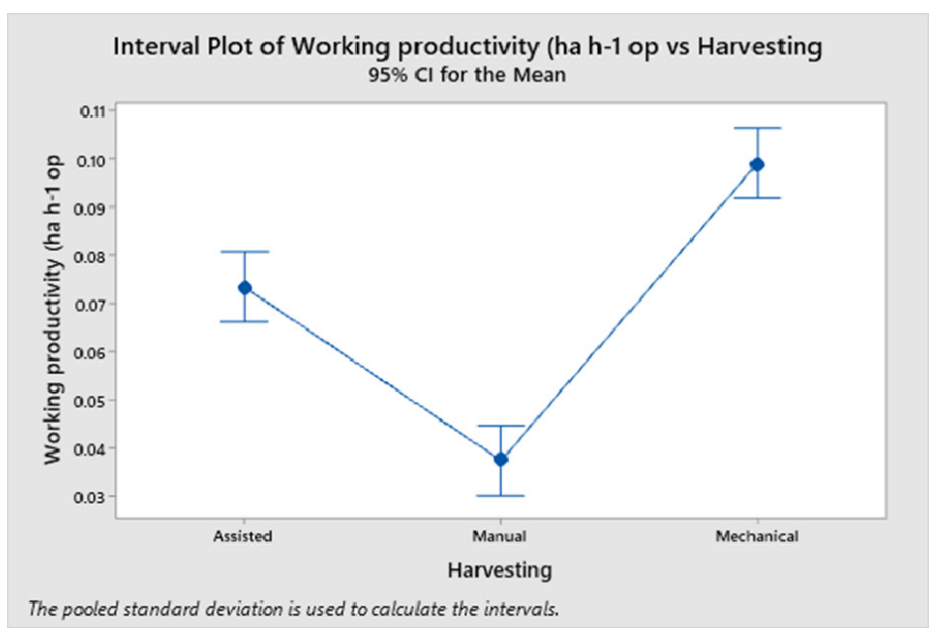

Figure 6. Results of Tukey method with a CI (Confidence Interval) of 95\%, applied to the raw data of working productivity for the three harvest tests $(p$-value $=0.000)$.

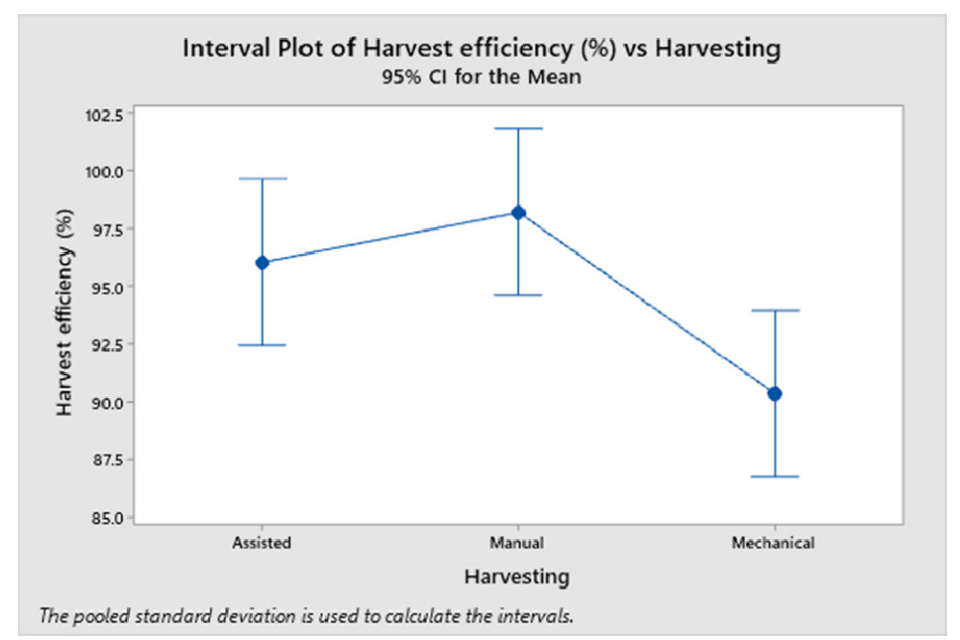

Figure 7. Results of Tukey method with a CI (Confidence Interval) of 95\%, applied to the raw data of working efficiency for the three harvest tests $(p$-value $=0.023)$.

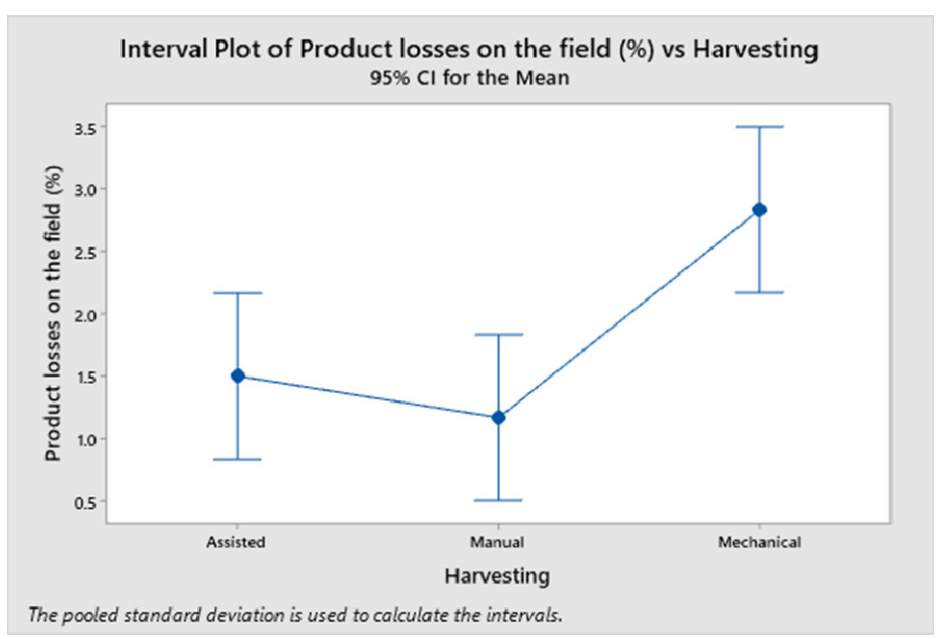

Figure 8. Results of Tukey method with a CI (Confidence Interval) of 95\%, applied to the raw data of product losses on the field for the three harvest tests $(p$-value $=0.011)$. 


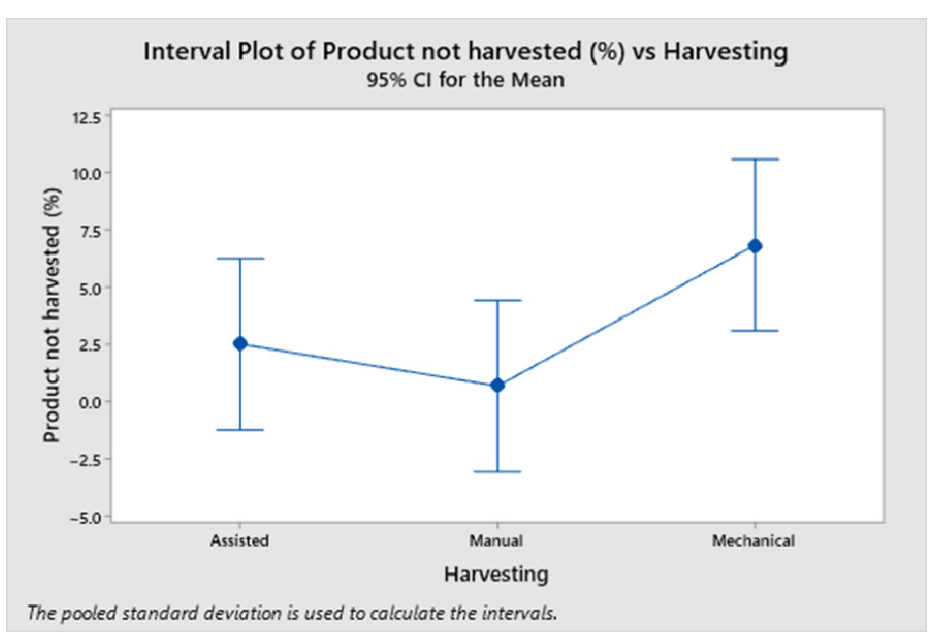

Figure 9. Results of Tukey method with a CI (Confidence Interval) of 95\%, applied to the raw data of the product not harvested for the three harvest tests $(p$-value $=0.070)$.

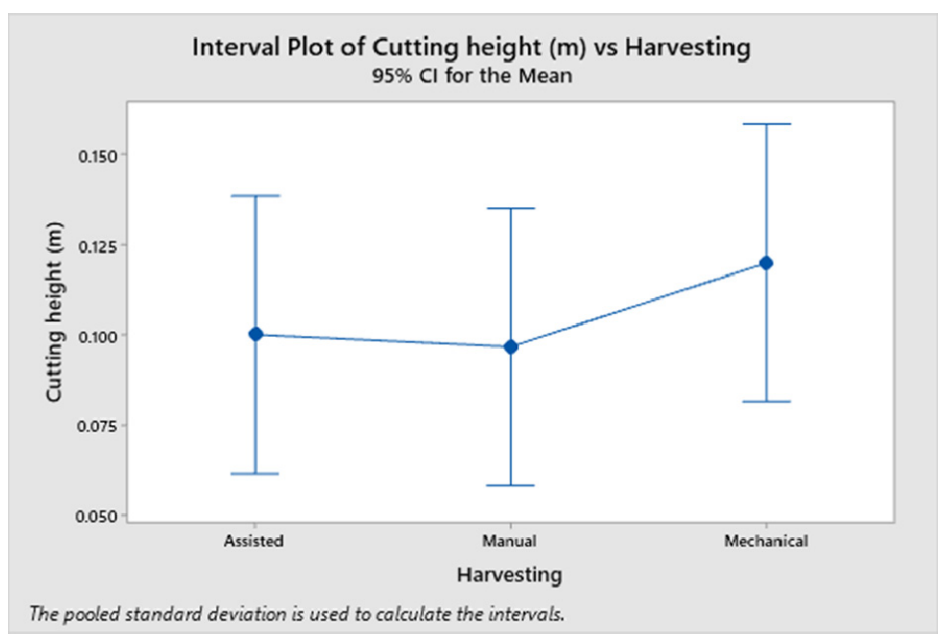

Figure 10. Results of Tukey method with a CI (Confidence Interval) of 95\%, applied to the raw data of cutting height for the three harvest tests ( $p$-value $=0.559)$.

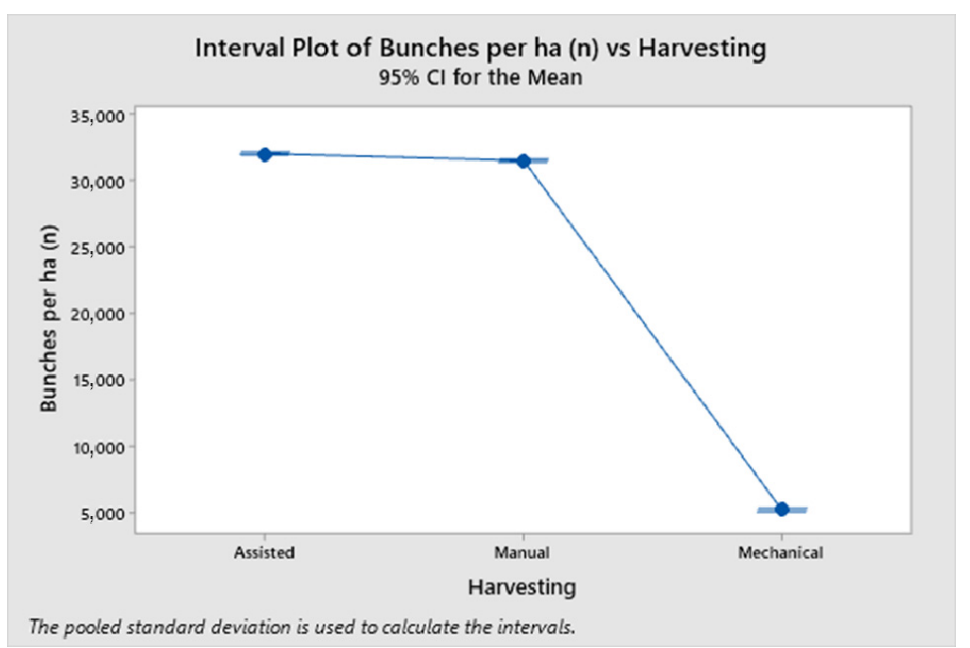

Figure 11. Results of Tukey method with a CI (Confidence Interval) of 95\%, applied to the raw data of bunches per ha for the three harvest tests $(p$-value $=0.000)$. 


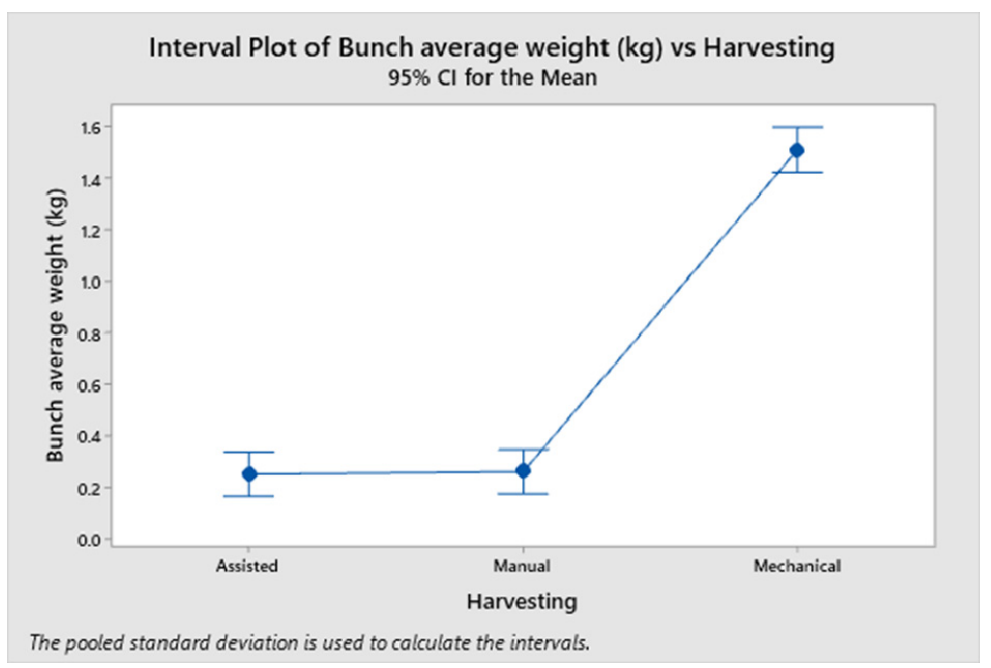

Figure 12. Results of Tukey method with a CI (Confidence Interval) of $95 \%$, applied to the raw data of bunch average weight for the three harvest tests $(p$-value $=0.000)$.

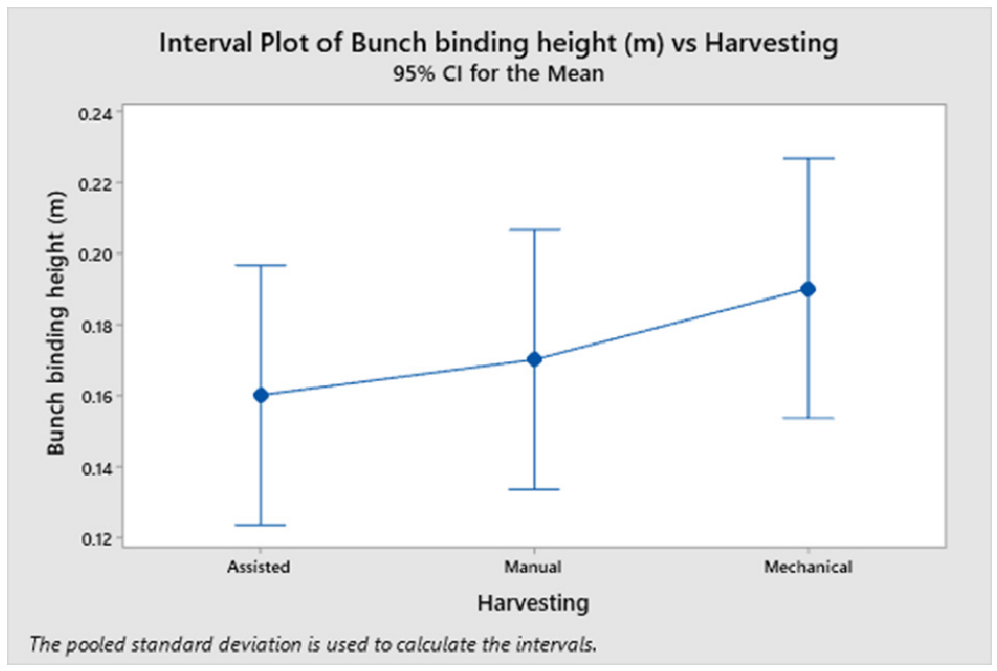

Figure 13. Results of Tukey method with a CI (Confidence Interval) of 95\%, applied to the raw data of bunch binding height for the three harvest tests ( $p$-value $=0.406$ ).

Furthermore, the harvest method also affects the product quality, in terms of exterior appearance, as the oregano bunches obtained by means of the three tested harvesting methods are not suitable for all the commercial uses of this plant species. In fact, the manually harvested bunches and those obtained by means of assisted harvesting can be commercialised for all possible uses (i.e., herb production, essential oil extraction and food) without packaging in local markets or after packaging for large-scale retail trade or export. In contrast, the mechanically harvested bunches can be used for essential oil extraction and/or as shelled food (i.e., flavourings).

\section{Conclusions}

The results of this research provide farmers with some suggestions aimed at significantly reducing the production cost of oregano in "marginal" hilly areas.

In fact, the modified reaper-binder and the edge trimmer allowed us to achieve working capacity and productivity rates about five and four times, respectively, higher than those manually obtained.

Yet, the harvest quality achieved using the modified machine was lower than that manually obtained: it resulted in bunches having a weight about six times higher than 
those manually harvested and required by the market, while the related binding height was slightly higher than that of manual harvesting. Moreover, the modified reaper-binder allowed us to achieve a harvest efficiency slightly lower than that of manual harvesting, due to both higher product losses on the field and a higher amount of product not harvested. Thus, the reaper-binder can minimise harvest time and, therefore, cost, while allowing us to obtain bunches slightly bigger than those manually harvested, even if it requires an initial investment cost.

In contrast, the edge trimmer allowed us to achieve working capacity and productivity rates slightly lower than the reaper-binder but about four times higher than in manual harvesting.

Therefore, the edge trimmer could be used by farmers that cultivate and manually harvest oregano on small areas of land: they could invest a small amount of capital to increase the working capacity and productivity while achieving a working quality similar to that of manual harvesting. Thus, the edge trimmer can be a cheap solution for reducing the harvest time and cost.

The reaper-binder allows us to decrease the total harvest time by ca. $81 \%$, while the edge trimmer reduces it by ca. 50\% compared with manual harvesting.

Moreover, the manually harvested bunches and those obtained using the edge trimmer can be commercialised for all possible uses, while those mechanically harvested can be used for essential oil extraction and/or as shelled food (flavourings).

Therefore, from the results of this research, it is possible to deduce that mechanical and assisted harvesting is fundamental for Origanum vulgare L. cultivation and that the production of fresh and/or dry oregano and its essential oil can play a key role in improving the economy of areas of both inland Sicily and other Mediterranean regions. Thus, mechanised oregano crop harvesting could be spread to these areas, which are often cultivated with low-profit herbaceous plant species or lie fallow, in order to increase the farmers' incomes and job opportunities, as well as preventing or minimising hydrogeological instability, comprising surface soil erosion, landslides, floods and water stagnation [14]. This profit increase would tend to stop the abandonment of the above areas by farmers, who also undertake the role of environmental protectors.

Author Contributions: Conceptualization, A.C. and S.O.; methodology, S.O.; software, S.O.; validation, A.C., M.M.M., S.C. and S.O.; formal analysis, C.G.; investigation, M.M.M. and C.G.; resources, S.C. and M.M.M.; data curation, A.C. and C.G.; writing-original draft preparation, A.C. and S.O.; writing-review and editing, A.C., C.G. and S.O.; visualization, M.M.M.; supervision, A.C. and S.O.; project administration, S.C. and M.M.M.; funding acquisition, C.G. All authors have read and agreed to the published version of the manuscript.

Funding: This work was funded by Rural Development Plan Sicily 2014-2020, Measure 16.1, as part of the Research Project Val.Inn.P.O. (Validation of innovative protocols for the production of aromatic plants grown in Sicily).

Institutional Review Board Statement: Not applicable.

Informed Consent Statement: Not applicable.

Acknowledgments: The authors acknowledge: i. Stefano Barone, of the Department of Agricultural, Food and Forestry Sciences of Palermo University, for the statistical analysis of the collected data; ii. Maria Luisa Cerrito of ORSA (Sicilian Regional Observatory for Environment) Association, for administrative support.

Conflicts of Interest: The authors declare no conflict of interest.

\section{References}

1. Skoula, M.; Harborne, J.B. The taxonomy and chemistry of Origanum. In Oregano: The Genera Origanum and Lippia; Kintzios, S., Ed.; Taylor and Francis: London, UK; New York, NY, USA, 2002; pp. 67-108.

2. Kokkini, S. Taxonomy, diversity and distribution of Origanum species. In Proceedings of the IPGRI International Workshop on Oregano, Bari, Italy, 8-12 May 1996; Padulosi, S., Ed.; CIHEAM: Bari, Italy, 1997; pp. 122-132. 
3. Asdal, A.; Galambosi, B.; Bjorn, G.; Olsson, K.; Pihlik, U.; Radušiene, J. Spice and medicinal plants in the Nordic and Baltic countries. In Report from a Project Group at the Nordic Gene Bank, Conservation of Genetic Resources; NGB: Alnarp, Norway, 2006; p. 157.

4. Ietswaart, J.H. A Taxonomic Revision of Genus Origanum (Labiatae); Leiden Botanical Series 4; Leiden University Press: The Hague, The Netherlands; Boston, MA, USA; London, UK, 1980.

5. Weglarz, Z.; Kosakowska, O.; Przybył, J.L.; Pióro-Jabrucka, E.; Bączek, K. The quality of Greek oregano (O. vulgare L. subsp. hirtum (Link) Ietswaart) and common oregano (O. vulgare L. subsp. vulgare) cultivated in the temperate climate of Central Europe. Foods 2020, 9, 1671. [CrossRef]

6. Napoli, E.; Giovino, A.; Carrubba, A.; How Yuen Siong, V.; Rinoldo, C.; Nina, O.; Ruberto, G. Variations of essential oil constituents in oregano (Origanum vulgare subsp. viridulum (=O. heracleoticum) over cultivation cycles. Plants 2020, 9, 1174. [CrossRef]

7. Skoufogianni, E.; Solomou, A.D.; Danalatos, N.G. Ecology, cultivation and utilization of the aromatic Greek oregano (Origanum vulgare L.): A review. Not. Bot. Horti Agrobot. Cluj-Napoca 2019, 47, 545-552. [CrossRef]

8. Amirante, P. Macchine ed Impianti per la Coltivazione Dell'origano (Machines and Plants for Oregano Cultivation). 2020. Available online: www.researchgate.net (accessed on 30 November 2021).

9. Padulosi, S. Promoting the conservation and use of underutilized and neglected crops. In Proceedings of the IPGRI International Workshop on Oregano, Bari, Italy, 8-12 May 1996; CIHEAM, Institute of Plant Genetics and Crop Plant Research, Gatersleben/International Plant Genetic Resources Institute: Rome, Italy, 1996.

10. Regione Siciliana. Portale Dell'innovazione. La Coltivazione Dell'origano. Nina, O. La Coltivazione Dell'origano-Esperienze di Tre Anni Nel Territorio di Aragona (The Cultivation of Oregano-Experiences of Three Years in the Territory of Aragona). Regione Siciliana-Assessorato Agricoltura e Foreste-Distretto Monti Sicani-SOAT di Aragona (Agrigento). Available online: https:/ / www.yumpu.com/it/document/view/6198452/la-coltivazione-dellorigano-portale-dellinnovazione-regione (accessed on 21 December 2021)

11. Carrara, M.; Catania, P.; Comparetti, A.; Febo, P.; Morello, G.; Orlando, S. First tests of mechanical harvest of Origanum vulgare L. In Proceedings of the XXX CIOSTA-CIGR V Congress, Turin, Italy, 22-24 September 2003; pp. 225-230.

12. Leto, C.; La Bella, S.; Tuttolomondo, T.; Licata, M.; Carrara, M.; Febo, P.; Catania, P.; Comparetti, A.; Orlando, S. Response of Origanum vulgare L. to different plant densities and first results of mechanical harvest. Agric. Mediterr. 2003, 133, 141-148.

13. Barone, S.; Lo Franco, E. Statistical and Managerial Techniques for Six Sigma Methodology. Theory and Application; John Wiley \& Sons: Chichester, UK, 2012; pp. 1-382. ISBN 978-0-470-71183-5. [CrossRef]

14. Puccio, D.; Comparetti, A.; Greco, C.; Raimondi, S. Proposal of a Nomenclature for Hydrogeological Instability Risks and Case Studies of Conservative Soil Tillage for Environmental Protection (review paper). Land 2022, 11, 108. [CrossRef] 